\title{
Erratum
}

Correction to the paper entitled

Transcending Paradox: The Chinese "Middle Way" Perspective, by Ming-Jer Chen

published in Asia Pacific Journal of Management

Volume 19, Issue 2/3, August 2002, 179-199

Several of the Chinese Characters within the text printed incorrectly and should have appeared as follows:

\section{Pages 183-184:}

\section{Chinese "Middle Way" Thinking}

Zhong guo, the Mandarin word for China, literally translates as "middle kingdom." The term is often mistakenly understood to mean that the Chinese see themselves as a superior people, occupying the center of the universe. In another misconception, "middle" is construed as "average" or "mean" (a misunderstanding propagated by the translated title of Confucius's work: The Book of Means). The term's philosophical origins are deeply rooted in the "middle way" teachings of such influential philosophers as Confucius and Lao Tzu (the founder of Taoism), where we find its true meaning. In its intended sense, the word "middle" conveys a dynamic concept, an active "harmonious integration" of opposites rather than a reactive compromise between them. All things in the universe, the Chinese believe, contain competing tendencies that must be balanced. The philosophical basis of the "middle kingdom" calls for maintaining an integrated life by balancing these extremes. In this way of thinking, opposite elements constitute an integrated whole.

Chinese culture today continues to place a high value on the middle way. Confucian philosophy recommends zhong he (中和), a concept based on middle way thinking (literally, "middle way," zhong, and "harmony," he) as the key to obtaining prosperity: "If zhong he is reached," writes Confucius in the Book of Means, "heaven and earth will be in place, and all things will grow." In this view, a system is harmonious only when it has achieved a balance between paradoxical tendencies. The middle way philosophy, therefore, embraces two opposing but interdependent ideas: holism and paradox.

\section{Holism}

In many respects, Chinese and Western worldviews are philosophically opposed. Dating to the pre-Socratic philosophy of Democritus (460-360 B.C.), Western thinking has been characterized by its analytical view, the parsing of reality into independent objects of study. Indeed, the Greek roots of "analysis" denote a "loosening" or "breaking apart." In accord with this "atomization" approach to the universe, Western philosophy has generally 
considered such opposing ideas as self and other, life and death, good and evil-in fact, human existence in general — as paradoxical and therefore irreconcilable (Schneider, 1990).

By contrast, Chinese thinking has traditionally embraced an integrative view of the world. In the Eastern conception of holism, all things in life are inseparable from their opposites. Individual elements are seen as integrated pieces composing a larger whole. The cornerstone of this philosophy is the interdependency of relationships, and thus family, spirituality, and social connections are not considered to be separate-rather, every aspect of life is interconnected (Chu, 1999). David Ho, a prominent HIV/AIDS researcher and Time magazine's "Man of the Year" for 1996, explained the manifestation of this belief: "I may be a wise scholar, a famous businessman or a good father and husband, but until I am all, I have not succeeded" (Chen, 2001, p. 90).

The idea of self-other (or holistic) integration, underlying the philosophies of all influential Chinese thinkers (including Sun Tzu, as well as Confucius and Lao Tzu), pervades Chinese culture. Chinese thinking stresses that self and other are interdependent opposites that can only be defined together, as part of a pair. In this way of thinking, self and other are not diametrically opposed but are dual building blocks that combine to form a greater whole. The idea is captured in the Chinese expression, ren zhe ren ye (人者仁也): "the meaning of person (人) is ren (仁)," in which the character ren (仁) means humanity, as well as core or seed, and comprises the characters for "two" (二) and "person" ( 人). Thus, in the Chinese perspective, no person exists except in relationship to another (Chen, 2001, p. 45). 